\title{
Calculation of Raman intensities for the torsional vibrations of ethyl halides
}

David F. Bocian

G. Alan Schick

J. Kathleen Hurd

Robert R. Birge

Follow this and additional works at: https://bearworks. missouristate.edu/articles-cnas

\section{Recommended Citation}

Bocian, David F., G. Alan Schick, J. Kathleen Hurd, and Robert R. Birge. "Calculation of Raman intensities for the torsional vibrations of ethyl halides." The Journal of Chemical Physics 76, no. 10 (1982):

4828-4833.

This article or document was made available through BearWorks, the institutional repository of Missouri State University. The work contained in it may be protected by copyright and require permission of the copyright holder for reuse or redistribution.

For more information, please contact BearWorks@library.missouristate.edu. 


\title{
Calculation of Raman intensities for the torsional vibrations of ethyl halides
}

\author{
David F. Bocian, G. Alan Schick, J. Kathleen Hurd, and Robert R. Birge \\ Department of Chemistry, University of California, Riverside, California 92521 \\ (Received 7 December 1981; accepted 4 February 1982)
}

\begin{abstract}
Raman intensities are calculated for the torsional vibrations of $\mathrm{CH}_{3} \mathrm{CH}_{2} \mathrm{Cl}, \mathrm{CH}_{3} \mathrm{CH}_{2} \mathrm{Br}, \mathrm{CH}_{3} \mathrm{CH}_{2} \mathrm{I}$, $\mathrm{CH}_{3} \mathrm{CHCl}_{2}$, and $\mathrm{CH}_{3} \mathrm{CHBr}_{2}$ using an anisotropic atom-point dipole interaction model to calculate the elements of the molecular polarizability tensor. The calculated relative intensities for the members of the $\Delta v=2$ torsional overtone progression of each of the ethyl halides are in good agreement with experiment. It is predicted that electrically anharmonic terms contribute substantially to the Raman intensities of these transitions. The $\Delta v=1$ torsional transitions of the five molecules are predicted to be 20-30 times more intense than the overtones (although these transitions are not observed because of broadband contours and interference from other vibrational modes). Electrically anharmonic terms in the polarizability expansions also contribute substantially to the intensity of the fundamentals.
\end{abstract}

\section{INTRODUCTION}

Gas-phase Raman spectroscopic studies of largeamplitude, low-frequency vibrations of small molecules have revealed unusually intense $\Delta v=2$ overtone transitions. ${ }^{1}$ The puckering vibrations of four-membered rings and five-membered rings containing one double bond $\mathrm{d}^{2-12}$ and the torsional vibrations of molecules containing methyl tops ${ }^{13-16}$ exhibit relatively intense $\Delta v=2$ overtones which are in some cases stronger than the $\Delta v=1$ fundamentals, even though the latter transitions are Raman allowed. The unusually large intensity observed for the $\Delta v=2$ transitions relative to the $\Delta v=1$ transitions is in part due to the fact that the overtones are totally symmetric, exhibiting sharp, well defined $Q$ branches, whereas the fundamentals are in many cases non-totally symmetric, exhibiting broadband contours with weak $Q$ branches. ${ }^{17}$ It is known, however, in the case of the puckering vibrations of ring molecules, that differences in the band contours are not the only factor determining the observed relative intensities of the two sets of transitions. ${ }^{18}$ We recently reported the calculation of molecular polarizability expansions and Raman intensities for the puckering vibrations of a number of small ring molecules (cyclobutane, ${ }^{18(2)}$ trimethylene oxide, ${ }^{18(2)}$ trimethyleneimine, ${ }^{18(b)}, 2,5$-dihydropyrrole, ${ }^{18(b)}$ cyclopentene, ${ }^{18(\mathrm{c})}$ and 2,5-dihydrofuran $\left.{ }^{18(\mathrm{c})}\right)$. These calculations predict unusually large second-order (electrically anharmonic) terms in the expansions of the molecular polarizability tensor elements in the ring puckering coordinate $\left[\left|\left(\partial^{2} \alpha_{\mu \nu} / \partial Z^{2}\right)_{0}\right| \gg 0\right]$. The large electrical anharmonicity results in intense calculated $\Delta v=2$ overtones, in agreement with experiment.

The appearance of $\Delta v=2$ methyl torsional overtones in the Raman spectrum is undoubtedly due to substantial electrical anharmonicity in the torsional oscillation. ${ }^{13.14}$ Thus far, however, no calculations of polarizability expansions and Raman intensities have been reported for methyl torsional vibrations. Other experimental means of qualitatively assessing the importance of electrical anharmonicity, such as comparing the relative intensities of the $\Delta v=1$ and $\Delta v=2$ progressions, are not generally possible because the fundamental transitions are not observed for most of the molecules studied experimentally. The apparent absence of the $\Delta v=1$ transitions in the Raman spectrum is due to several factors, including broadband contours and interference from other low frequency vibrations or the wing of the Rayleigh line.

In this paper, we report the calculation of Raman intensities for the torsional vibrations of a series of ethyl halides $\left(\mathrm{CH}_{3} \mathrm{CH}_{2} \mathrm{Cl}, \mathrm{CH}_{3} \mathrm{CH}_{2} \mathrm{Br}, \mathrm{CH}_{3} \mathrm{CH}_{2} \mathrm{I}\right.$, $\mathrm{CH}_{3} \mathrm{CHCl}_{2}$, and $\mathrm{CH}_{3} \mathrm{CHBr}_{2}$ ). Both the $\Delta v=1$ and $\Delta v=2$ torsional transitions of these molecules are allowed in the Raman spectrum, but only the overtone transitions are observed. ${ }^{13,14}$ The $\Delta v=2$ transitions of all the ethyl halides exhibit a non-Boltzmann intensity distribution with the $0-2$ transition comparable in intensity to the $1-3$ transition. We first review the method for calculating the molecular polarizability and then discuss the origin of the Raman intensity. We then give expansions of the molecular polarizability tensor elements as trigonometric series in the torsional angle and present the calculated Raman intensities.

\section{THEORETICAL SECTION}

\section{A. Anisotropic atom-point dipole interaction model of the polarizability}

The expansions of the molecular polarizability tensor elements as a function of the torsional angle were calculated using the anisotropic atom-point dipole interaction (AAPDI) model developed by Birge. ${ }^{19}$ A complete description of the model is given in Ref. 19. The use of the AAPDI model for the determination of the polarizability of the ethyl halides is essentially identical to that used in our previous calculations on ring molecules $^{18(a)}$ and we briefly outline below the parametrization of the model for the halogenated hydrocarbons.

The average atomic polarizabilities $\left(\bar{\alpha}_{A}\right)$ for hydrogen (alkane), carbon (alkane), chlorine, bromine, and iodine were taken from Ref. 20 and are listed in Table I. A comparison of the calculated mean molecular polarizabilities with the experimental values determined using the Lorentz-Lorenz relationship ${ }^{21,22}$ is presented in Table II. The average error in the calcu- 
TABLE I. Atomic parameters used in the anisotropic atompoint dipole interaction calculations on ethyl halides. ${ }^{2}$

\begin{tabular}{clcc}
\hline \hline Atom type & $\bar{\alpha}_{A}\left(\mathrm{~A}^{3}\right)^{\mathrm{b}}$ & $\xi_{A^{\mathrm{c}}}$ & $g_{\mathrm{AA}}(\mathrm{eV})^{\mathrm{d}}$ \\
\hline $\mathrm{H}$ & 0.135 & 0.430 & 12.848 \\
$\mathrm{C}$ & 0.878 & 0.347 & 10.333 \\
$\mathrm{Cl}$ & 1.91 & $0.030^{\circ}$ & 10.366 \\
$\mathrm{Br}$ & 2.88 & $0.002^{\circ}$ & 8.838 \\
$\mathrm{I}$ & 4.69 & $0.000^{\circ}$ & 9.382 \\
\hline
\end{tabular}

2Optimized for experimental molecular polarizabilities based on sodium $D$ line (5893 $\AA$ ) refractive index data (see Ref. 19).

${ }^{b}$ Average atomic polarizabilities used to determine the mean molecular polarizabilities using the isotropic atom approximation $\left(\xi_{A}^{\prime} s=0\right)$. These values are then used as initial guesses for the AAPDI calculation (see Ref. 19).

A tomic anisotropy constants. The values for $\mathbf{H}$ and $\mathrm{C}$ were taken from Table I of Ref. 19, assuming transferability for similar atomic environments.

dOne center valence state electron repulsion integrals taken from Ref. 34.

-Optimized for the corresponding methyl halide using the procedures outlined in Ref. 19 (see the text).

lated mean polarizability is only $3.4 \%$ which is comparable to experimental uncertainty. A worst case error of $6.7 \%$ is observed for $\mathrm{CH}_{3} \mathrm{CH}_{2} \mathrm{Cl}$ (Table II), but the magnitude of this error is too small to have any significant impact on the calculated expansions of the molecular polarizability elements as a function of torsional angle.

The atomic anisotropy constants $\left(\xi_{A}\right)$ for hydrogen and carbon were taken from Table I of Ref. 19 assuming transferability for similar atomic environments. The
TABLE II. Experimental and calculated molecular polarizabilities for selected ethyl halides.

\begin{tabular}{|c|c|c|c|c|}
\hline \multirow[b]{2}{*}{ Molecule } & \multirow[b]{2}{*}{$n_{D}^{2}$} & \multirow[b]{2}{*}{$d^{2}(\mathrm{~g} / \mathrm{ml})$} & \multicolumn{2}{|c|}{$\bar{\alpha}\left(\AA^{3}\right)$} \\
\hline & & & expt. ${ }^{b}$ & calc. $^{\circ}$ \\
\hline $\mathrm{CH}_{3} \mathrm{CH}_{2} \mathrm{Cl}$ & 1.3676 & 0.8978 & 6.41 & 6.84 \\
\hline $\mathrm{CH}_{3} \mathrm{CH}_{2} \mathrm{Br}$ & 1.4239 & 1.4604 & 7.55 & 7.83 \\
\hline $\mathrm{CH}_{3} \mathrm{CH}_{2} \mathrm{I}$ & 1.5133 & 1.9358 & 9.55 & 9.70 \\
\hline $\mathrm{CH}_{3} \mathrm{CHCl}_{2}$ & 1.4164 & 1.1757 & 8.38 & 8.67 \\
\hline $\mathrm{CH}_{3} \mathrm{CHBr}_{2}$ & 1,5128 & 2.0555 & 10.9 & 10.7 \\
\hline
\end{tabular}

${ }^{a}$ The sodium $D$ line refractive indices $\left(n_{D}\right)$ and the ambient temperature densities $(d)$ were taken from Ref. 22.

Mean molecular polarizabilities as determined using the Lorentz-Lorenz equation (Ref. 21) and the corresponding values of $n_{D}$ and $d$.

'Mean molecular polarizabilities calculated using a point dipole interaction treatment (Sec. II A) and the atomic polarizability parameters from Table I.

corresponding values for chlorine, bromine, and iodine were optimized to best reproduce the experimental components of the molecular polarizability tensors of the methyl halides. The experimental data were taken from the compilations given in Table III of Ref. 20. The results are given in Table $I$ and indicate that the halogen atoms require surprisingly small atomic anisotropy constants to generate the correct molecular anistropy within the AAPDI formalism. In fact, bromine and iodine are predicted to be essentially isotropic $\left(\xi_{A} \sim 0\right)$. This observation is not surprising because most of the polarizability of the latter atoms is associated with the composite properties of the inner shell electrons. The bonding environment of the single va-

TABLE III. Calculated polarizability expansion coefficients for the torsional vibrations of ethyl halides.

\begin{tabular}{|c|c|c|c|c|c|c|c|}
\hline \multirow[b]{2}{*}{ Molecule } & \multirow[b]{2}{*}{$n^{\mathrm{a}}$} & \multicolumn{4}{|c|}{$\begin{array}{l}\text { Cosine expansion } \\
\text { coefficients }\left(a_{n}^{\mu \nu}\right)\end{array}$} & \multicolumn{2}{|c|}{$\begin{array}{l}\text { Sine expansion } \\
\text { coefficients }\left(b_{n}^{\mu \nu}\right)\end{array}$} \\
\hline & & $\alpha_{x x}\left(\AA^{3}\right)$ & $\alpha_{y y}\left(\AA^{3}\right)$ & $\alpha_{z E}\left(\AA^{3}\right)$ & $\alpha_{y x}\left(\AA^{3}\right)$ & $\alpha_{\operatorname{mx}}\left(\AA^{3}\right)$ & $\alpha_{x y}\left(\AA^{3}\right)$ \\
\hline \multirow[t]{4}{*}{$\mathrm{CH}_{3} \mathrm{CH}_{2} \mathrm{Cl}$} & 0 & 6.10 & 6.10 & 8.30 & 0.0 & 0.0 & 0.0 \\
\hline & 1 & 0.257 & -0.257 & 0.0 & -0.0294 & -0.0294 & 0.257 \\
\hline & 2 & -0.831 & 0.831 & 0.0 & -0.162 & 0.162 & 0.831 \\
\hline & 3 & 0.0615 & 0.0615 & -0.118 & 0.0 & 0.0 & 0.0 \\
\hline \multirow[t]{4}{*}{$\mathrm{CH}_{3} \mathrm{CH}_{2} \mathrm{Br}$} & 0 & 7.15 & 7.15 & 9.17 & 0.0 & 0.0 & 0.0 \\
\hline & 1 & 0.356 & -0.356 & 0.0 & -0.0632 & -0.0632 & 0.356 \\
\hline & 2 & -1.05 & 1.05 & 0.0 & -0.228 & 0.228 & 1.05 \\
\hline & 3 & 0.0748 & 0.0748 & -0.142 & 0.0 & 0.0 & 0.0 \\
\hline \multirow[t]{4}{*}{$\mathrm{CH}_{3} \mathrm{CH}_{2} \mathrm{I}$} & 0 & 9.14 & 9.14 & 10.8 & 0.0 & 0.0 & 0.0 \\
\hline & 1 & 0.740 & -0.740 & 0.0 & -0.0675 & -0.0675 & 0.740 \\
\hline & 2 & -1.10 & 1.10 & 0.0 & -0.492 & 0.492 & 1.10 \\
\hline & 3 & 0.199 & 0.199 & -0.394 & 0.0 & 0.0 & 0.0 \\
\hline \multirow[t]{4}{*}{$\mathrm{CH}_{3} \mathrm{CHCl}_{2}$} & 0 & 8.43 & 8.43 & 9.12 & 0.0 & 0.0 & 0.0 \\
\hline & 1 & -0.183 & 0.183 & 0.0 & 0.431 & 0.431 & -0.183 \\
\hline & 2 & 1.42 & -1.42 & 0.0 & -0.136 & 0.136 & -1.42 \\
\hline & 3 & -0.0137 & -0.0137 & 0.0470 & 0.0 & 0.0 & 0.0 \\
\hline \multirow[t]{4}{*}{$\mathrm{CH}_{3} \mathrm{CHBr}_{2}$} & 0 & 10.8 & 10.8 & 10.6 & 0.0 & 0.0 & 0.0 \\
\hline & 1 & -0.217 & 0.217 & 0.0 & 0.616 & 0.616 & -0.217 \\
\hline & 2 & 2.22 & -2.22 & 0.0 & -0.182 & 0.182 & -2.22 \\
\hline & 3 & -0.0360 & -0.0360 & 0.0964 & 0.0 & 0.0 & 0.0 \\
\hline
\end{tabular}

$n$ is the index of the Fourier expansion, i.e., $\alpha_{\mu \nu}=\sum_{n} a_{n}^{\mu \nu} \cos n \theta$ or $\alpha_{\mu \nu}=\sum_{n} b_{n}^{\mu \nu} \sin n \theta$. 
lence electron is therefore of diminished relative importance in defining the anisotropic character of the atomic polarizability tensor in the molecular environment.

\section{B. Origin of the Raman intensity}

The intensity of a Stokes Raman transition is given by the following expression ${ }^{23}$ :

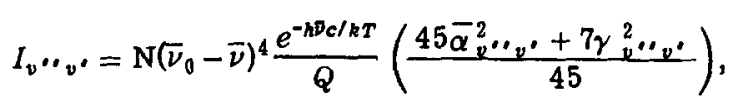

where $v^{\prime \prime}$ and $v^{\prime}$ are the initial and final vibrational states, $N$ is a constant, $\bar{\nu}_{0}$ and $\bar{\nu}$ are the frequencies of the incident radiation and the vibrational mode, $Q$ is the partition function, and $\bar{\alpha}$ and $\gamma^{2}$ are the invariants of the molecular polarizability tensor, defined by

$$
\begin{aligned}
\bar{\alpha}= & (1 / 3)\left(\alpha_{x x}+\alpha_{y y}+\alpha_{z z}\right), \\
\gamma^{2}= & (1 / 2)\left[\left(\alpha_{x x}-\alpha_{y y}\right)^{2}+\left(\alpha_{y y}-\alpha_{z z}\right)^{2}+\left(\alpha_{z z}-\alpha_{x x}\right)^{2}\right. \\
& \left.+6\left(\alpha_{x y}^{2}+\alpha_{y z}^{2}+\alpha_{z x}^{2}\right)\right] .
\end{aligned}
$$

The molecular polarizability tensor elements for tor sional vibrations are most easily expressed as trigonometric series in the internal rotation angle $\theta .^{24,25}$ The trigonometric functions have the same symmetry as the irreducible representations of the internal rotation group, unlike the angle $\theta$ itself. ${ }^{26,27}$ In the internal rotation group $D_{3},{ }^{28}$ the polarizability tensor elements $\alpha_{x x}+\alpha_{y y}$ and $\alpha_{x x}$ are of $A_{1}$ symmetry and the elements $\left(\alpha_{x x}-\alpha_{y y}, \alpha_{x y}\right)$ and $\left(\alpha_{y z}, \alpha_{z x}\right)$ are of $E$ symmetry. With the axis of the methyl top defined as the $z$ axis and choosing the plane of symmetry of the staggered, $\theta=0^{\circ}$ (or eclipsed, $\theta=180^{\circ}$ ), form of the ethyl halides as the $y z$ plane, the polarizability tensor elements are expressed as follows:

$A_{1}$ symmetry

$$
\left.\begin{array}{l}
\alpha_{x x}+\alpha_{y y}=\sum_{n} a_{n}^{x x+y y} \cos n \theta, \\
\alpha_{x x}=\sum_{n} a_{n}^{\alpha z} \cos n \theta,
\end{array}\right\} n=0,3,6,9, \ldots,
$$

E symmetry

$$
\left.\begin{array}{l}
\alpha_{x x}-\alpha_{y y}=\sum_{n} a_{n}^{x x-y y} \cos n \theta, \\
\alpha_{x y}=\sum_{n} b_{n}^{x y} \sin n \theta,
\end{array}\right\} n=1,2,4,5, \ldots,
$$

and

$$
\left.\begin{array}{l}
\alpha_{y \varepsilon}=\sum_{n} a_{n}^{y z} \cos n \theta, \\
\alpha_{z x}=\sum_{n} b_{n}^{z x} \sin n \theta,
\end{array}\right\} \quad n=1,2,4,5, \ldots,
$$

where $a_{n}^{\mu \nu}$ and $b_{n}^{\mu \nu}$ are the Fourier expansion coefficients (see Sec. III). A detailed discussion of the methods for determining the symmetry properties of the trigonometric functions can be found in Refs, 26 and 27. Finally, the matrix elements for the transition $v^{\prime}-v^{\prime \prime}$ are given by

$$
\left[\alpha_{\mu \nu}\right]_{v^{\prime \prime} \nu^{*}}=\left\{\begin{array}{l}
\sum_{n} a_{n}^{\mu \nu}\left\langle v^{\prime \prime}|\cos n \theta| v^{\prime}\right\rangle, \\
\sum_{n} b_{n}^{\mu \nu}\left\langle v^{\prime \prime}|\sin n \theta| v^{\prime}\right\rangle .
\end{array}\right.
$$

\section{CALCULATION OF THE POLARIZABILITY EXPANSIONS AND RAMAN INTENSITIES FOR THE TORSIONAL TRANSITIONS OF THE ETHYL HALIDES}

The expansions of the elements of the polarizability tensor in terms of trigonometric series in the internal rotation angle were obtained by calculating the polarizability (see Sec. II A) for conformations ranging from $\theta=0^{\circ}$ (staggered) to $\theta= \pm 180^{\circ}$ (eclipsed) in $\pm 30^{\circ}$ steps. The expansion coefficients, $a_{n}^{\mu \nu}$ and $b_{n}^{\mu \nu}$ were obtained by taking the 13 point Fourier cos or sin transform of the calculated values of the $\alpha_{\mu \nu}$ as a function of $\theta .{ }^{24}$ It was found that reducing the angular steps at which the polarizability was calculated from $30^{\circ}$ to $15^{\circ} \mathrm{did}$ not substantially alter the calculated expansion coefficients. The reference coordinate system in which the atomic displacements for the torsional motion were evaluated is one in which the methyl rotor axis is defined along the $z$ axis and the plane of symmetry of the staggered conformation of the ethyl halide is the $y z$ plane. This definition of the reference coordinate system results in molecular polarizability expansions in the form of Eq. (4).

The model used for the torsional motion of the ethyl halides is one in which all bond lengths and bond angles remain constant as only the methyl group rotates. The geometrical parameters for $\mathrm{CH}_{3} \mathrm{CH}_{2} \mathrm{Cl}$ and $\mathrm{CH}_{3} \mathrm{CH}_{2} \mathrm{Br}$ were taken from Ref. 29. The bond lengths and bond angles of $\mathrm{CH}_{3} \mathrm{CHCl}_{2}$ and $\mathrm{CH}_{3} \mathrm{CHBr}_{2}$ were taken to be the same as those in the respective monohalides with the XCX bond angles taken to be the same as the HCX bond angles of the latter molecules. The HCX bond angles of the dihalides were then calculated using relationships describing the interdependence of the bond angles. ${ }^{30}$ The $\mathrm{C}-\mathrm{I}$ bond length and $\mathrm{HCH}$ bond angle of $\mathrm{CH}_{3} \mathrm{CH}_{2} \mathrm{I}$ were taken to be the same as those in $\mathrm{CH}_{3} \mathrm{I}^{31}$ and the $\mathrm{HCI}$ bond angle was taken to be the same as the HCBr bond angle of bromoethane. ${ }^{29}$ The CCI bond angle was then calculated as described above. It should be noted that any reasonable changes in the bond lengths and bond angles of the equilibrium geometries do not significantly alter the calculated molecular polarizability expansion coefficients. ${ }^{18}$

The Raman intensities for the torsional transitions were determined using calculated expansions of the $\alpha_{\mu \nu}$ and Eqs. (1)-(3). The vibrational transition moments Eq. (5) were evaluated for the various eigenfunctions of the appropriate hindered internal rotor which were obtained by diagonalizing the Hamiltonian,

$$
H=-F\left(d^{2} / d \theta^{2}\right)+\frac{1}{2} \sum_{n} V_{n}(1-\cos n \theta), \quad n=3,6, \ldots,
$$

in a free internal rotation basis set of $20 \cos$ and 20 sin functions. In the Hamiltonian, $F$ is the internal rotation constant, and the $V_{n}$ are the potential energy constants. The kinetic and potential energy parameters for the ethyl halides were taken from Ref. 14. 
TABLE IV. Observed and calculated Raman intensities for the torsional transitions of ethyl halides.

\begin{tabular}{|c|c|c|c|c|c|}
\hline \multirow[b]{2}{*}{ Molecule } & \multirow[b]{2}{*}{ Transition } & \multirow{2}{*}{$\begin{array}{l}\text { Frequency } \\
\left(\mathrm{cm}^{-1}\right)^{\mathrm{a}}\end{array}$} & \multicolumn{3}{|c|}{ Relative intensity } \\
\hline & & & Observed $^{\mathrm{a}}$ & Calculation $I^{\mathrm{b}, \mathrm{c}}$ & Calculation $\mathrm{II}^{\mathrm{b}, \mathrm{d}}$ \\
\hline \multirow[t]{6}{*}{$\mathrm{CH}_{3} \mathrm{CH}_{2} \mathrm{Cl}$} & $0-1$ & 252 & $\cdots$ & 1.1 & 0.022 \\
\hline & $1-2$ & 236 & $\cdots$ & 0.65 & 0.013 \\
\hline & $2-3$ & 217 & $\ldots$ & 0.30 & $6.7 \times 10^{-3}$ \\
\hline & $0-2$ & 488 & $(0.037)$ & $(0.037)$ & $2.6 \times 10^{-4}$ \\
\hline & $1-3$ & 455 & 0.034 & 0.034 & $2.5 \times 10^{-4}$ \\
\hline & $2-4$ & 418 & 0.020 & 0.022 & $1.8 \times 10^{-4}$ \\
\hline \multirow[t]{6}{*}{$\mathrm{CH}_{3} \mathrm{CH}_{2} \mathrm{Br}$} & $0-1$ & 248 & $\cdots$ & 1.9 & 0,041 \\
\hline & $1-2$ & 233 & $\cdots$ & 1.1 & 0.026 \\
\hline & $2-3$ & 216 & $\cdots$ & 0.51 & 0.013 \\
\hline & $0-2$ & 482 & $(0.057)$ & $(0.057)$ & $4.8 \times 10^{-4}$ \\
\hline & $1-3$ & 449 & 0.054 & 0.053 & $4.7 \times 10^{-4}$ \\
\hline & $2-4$ & 412 & 0.038 & 0.035 & $3.4 \times 10^{-4}$ \\
\hline \multirow[t]{6}{*}{$\mathrm{CH}_{3} \mathrm{CH}_{2} \mathrm{I}$} & $0-1$ & 246 & $\cdots$ & 2.7 & 0.18 \\
\hline & $1-2$ & 231 & $\cdots$ & 1.8 & 0.11 \\
\hline & $2-3$ & 214 & $\cdots$ & 0.92 & 0.057 \\
\hline & $0-2$ & 476 & $(0.084)$ & $(0.084)$ & $2.0 \times 10^{-3}$ \\
\hline & $1-3$ & 446 & 0.084 & 0.084 & $2.0 \times 10^{-3}$ \\
\hline & $2-4$ & 407 & 0.026 & 0.060 & $1.5 \times 10^{-3}$ \\
\hline \multirow[t]{6}{*}{$\mathrm{CH}_{3} \mathrm{CHCl}_{2}$} & $0-1$ & 254 & $\cdots$ & 2.5 & 0.064 \\
\hline & $1-2$ & 240 & $\cdots$ & 1.6 & 0.039 \\
\hline & $2-3$ & 225 & $\cdots$ & 0.78 & 0.019 \\
\hline & $0-2$ & $495^{\circ}$ & $(0.083)^{\circ}$ & $(0.083)$ & $6.8 \times 10^{-4}$ \\
\hline & $1-3$ & $465^{\circ}$ & $0.11^{\circ}$ & 0.082 & $6.5 \times 10^{-4}$ \\
\hline & $2-4$ & $432^{e}$ & $\ldots e$ & 0.060 & $4.5 \times 10^{-4}$ \\
\hline \multirow[t]{6}{*}{$\mathrm{CH}_{3} \mathrm{CHBr}_{2}$} & $0-1$ & 255 & $\cdots$ & 5.7 & 0.12 \\
\hline & $1-2$ & 242 & $\cdots$ & 3.6 & 0.072 \\
\hline & $2-3$ & 277 & $\cdots$ & 1.8 & 0.035 \\
\hline & $0-2$ & 496 & $(0.19)$ & $(0.19)$ & $1.2 \times 10^{-3}$ \\
\hline & $1-3$ & 461 & 0.14 & 0.19 & $1.1 \times 10^{-3}$ \\
\hline & $2-4$ & $437^{r}$ & $\ldots{ }^{\prime}$ & 0.13 & $7.7 \times 10^{-4}$ \\
\hline
\end{tabular}

The frequencies and observed intensities of the $\Delta v=2$ transitions were taken from Ref. $13\left(\mathrm{CH}_{3} \mathrm{CH}_{2} \mathrm{Cl}_{\text {, }}\right.$ $\mathrm{CH}_{3} \mathrm{CH}_{2} \mathrm{Br}$ and $\left.\mathrm{CH}_{3} \mathrm{CH}_{2} \mathrm{I}\right)$ and Ref. $14\left(\mathrm{CH}_{3} \mathrm{CHCl}_{2}\right.$ and $\left.\mathrm{CH}_{3} \mathrm{CHBr}_{2}\right)$. The intensities were estimated from the peak heights in Figs, 1, 2, and 3 of Ref, 13 and Fig. 1 of Ref. 14. The observed intensity of the $0 \rightarrow 2$ transition of each molecule was set equal to the calculated value and used as the reference intensity. The frequencies of the $\Delta v=1$ transitions of $\mathrm{CH}_{3} \mathrm{CH}_{2} \mathrm{Cl}$ and $\mathrm{CH}_{3} \mathrm{CH}_{2} \mathrm{Br}$ were taken from the far infrared data reported in Refs. 32 and 33 , respectively. The $\Delta v=1$ torsional transitions of $\mathrm{CH}_{3} \mathrm{CH}_{2} \mathrm{I}, \mathrm{CH}_{3} \mathrm{CHCl}_{2}$, and $\mathrm{CH}_{3} \mathrm{CHBr}_{2}$ have not been well characterized in the far infrared so the listed frequencies are calculated values.

b The calculated intensities are in arbitrary units; however, the predicted relative intensities for a given transition of the different molecules can be directly compared.

${ }^{\circ}$ Calculated using the complete polarizability expansions in Table III.

${ }^{d}$ Calculated neglecting electrical anharmonicity by including only the first-order terms in the polarizability expansions in Table III.

${ }^{\text {T}}$ The frequencies and intensities of the $\Delta v=2$ transitions of $\mathrm{CH}_{3} \mathrm{CHCl}_{2}$ are perturbed by Fermi resonance with other vibrational modes. The listed frequencies are calculated values.

${ }^{\text {IT }}$ The $2 \rightarrow 4$ transition of $\mathrm{CH}_{3} \mathrm{CH}_{2} \mathrm{I}$ is not observed and the frequency reported is the calculated value.

A complete description of this method for solving the hindered internal rotor Hamiltonian, including a tabulation of the matrix elements for the potential function and the vibrational transition moments, is given in Ref. 25.

The polarizability expansion coefficients obtained for the ethyl halides are given in Table III. Nonzero expansion coefficients are also obtained for terms with $n>3$, but these are negligible compared to those listed in the table. Note that the expansions of $\alpha_{x x}$ and $\alpha_{y y}$ contain terms in all orders of $\cos n \theta$, since it is the symmetric and antisymmetric linear combinations of these elements rather than the elements themselves which transform according to the irreducible representations of the internal rotation group.

The relative Raman intensities calculated for the torsional transitions of the ethyl halides using the polarizability expansions given in Table III are listed along with the observed intensities in Table IV. The transitions are given in terms of the high barrier quantum number $v$, which is appropriate for the lowest torsional levels of the ethyl halides. ${ }^{13,14,32,33}$ The intensities are the total intensities for the transitions between the triply degenerate levels. The Raman spec- 
tra of $\mathrm{CH}_{3} \mathrm{CH}_{2} \mathrm{Cl}$ and $\mathrm{CH}_{3} \mathrm{CH}_{2} \mathrm{Br}$ simulated using the calculated intensities for the $\Delta v=2$ transitions are compared with the observed spectra in Figs. 1 and 2, respectively. The calculated relative intensities of the members of the $\Delta v=2$ progression are in excellent agreement with those observed for all the ethyl halides. ${ }^{13.14}$ The calculations also predict that the $\Delta v=1$ torsional transitions of the ethyl halides are approximately 20-30 times more intense than the $\Delta v=2$ transitions. Unfortunately, the fundamental transitions are not observed for any of the ethyl halides. It is not possible to verify that the $\Delta v=1$ transitions are actually absent from the Raman spectrum because the region of the spectrum where the torsional fundamentals are expected is partially obscured by other vibrational bands.

The contribution of electrically anharmonic terms (terms with $n \geq 2$ ) to the Raman intensities of the torsional vibrations can be determined by calculating the intensities using only the first-order terms in Table III. The intensities calculated using these terms are compared in Table IV with those determined using the complete polarizability expansions. The use of only the first-order terms results in calculated intensities for both the $\Delta v=1$ and $\Delta v=2$ progressions which are two orders of magnitude weaker than those determined using the complete expansions. Unfortunately, the relative intensities within either the $\Delta v=2$ or the $\Delta v=1$ progression do not change substantially when the electrically anharmonic terms are excluded. For example, the $0 \rightarrow 2$ and $1-3$ transitions of each of the ethyl halides are calculated to be of nearly equal intensity in both calculation I and calculation II. The exclusion of electrically anharmonic terms does result in a substantial decrease in the calculated intensity of the over tone progression relative to the fundamental progression. Of course, since the $\Delta v=1$ transitions are not

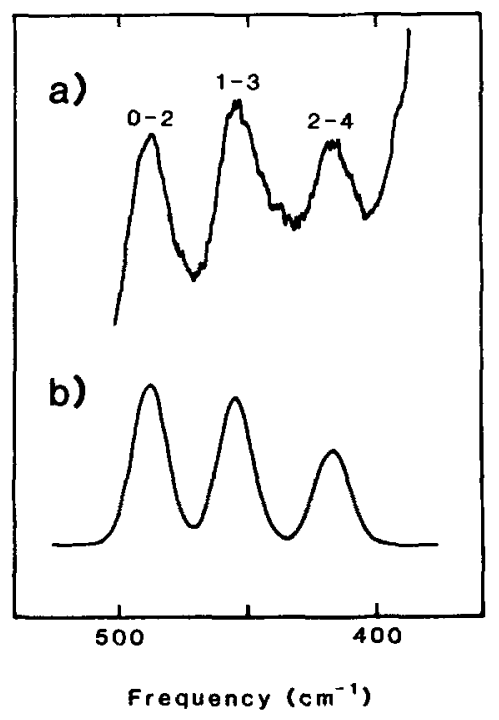

FIG. 1. (a) Observed (Ref. 13, reproduced by permission) and (b) calculated low-frequency gas-phase Raman spectra of $\mathrm{CH}_{3} \mathrm{CH}_{2} \mathrm{Cl}$. The spectrum was simulated using the polarizability expansions given in Table III. Gaussian profiles were used to represent the band shapes of the Raman lines.

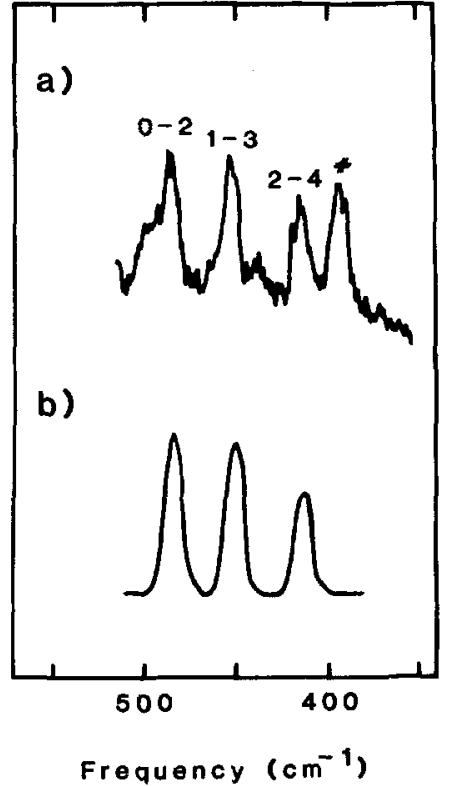

FIG. 2. (a) Observed (Ref. 13, reproduced by permission) and (b) calculated low-frequency gas-phase Raman spectra of $\mathrm{CH}_{3} \mathrm{CH}_{2} \mathrm{Br}$. The spectrum was simulated using the polarizability expansions given in Table III. Gaussian profiles were used to represent the band shapes of the Raman lines. The peak labeled with the symbol (\#) in the observed spectrum is not due to a torsional overtone.

observed, the relative importance of the electrically anharmonic terms cannot be determined experimentally.

\section{SUMMARY AND CONCLUSIONS}

The polarizability expansions calculated for the torsional oscillations of the ethyl halides result in calculated relative intensities for the $\Delta v=2$ overtones which are in excellent agreement with those observed. It is predicted that the $\Delta v=2$ transitions are 20-30 times less intense than the $\Delta v=1$ fundamentals (although the latter transitions are not observed). This intensity of the overtones relative to the fundamentals is still reasonably large and would account for the anomalously large strength of the tor sional progressions in the Raman spectra of the ethyl halides. Overall, the intensities of the $\Delta v=2$ overtones of the torsional vibrations of the ethyl halides relative to the $v=1$ fundamentals are somewhat smaller than those of the analogous progressions for the large amplitude puckering motion in small ring molecules in which the overtone transitions are in some cases as intense as the fundamentals. 18

\section{ACKNOWLEDGMENTS}

This work was supported by the Donors of the Petroleum Research Fund (D.F.B.), administered by the American Chemical Society; Research Corporation (D. F.B. ); the National Institutes of Health (R. R. B.); the National Science Foundation (R.R. B.); and the Committee on Research, University of California, Riverside (D. F. B. and R. R. B.). 
${ }^{1}$ For a review of gas-phase Raman studies of large-amplitude vibrations see C. J. Wurrey, J. R. Durig, and L. A. Carreira, in Vibrational Spectra and Structure, edited by J. R. Durig (Elsevier, New York, 1976), Vol. 5, pp. 121-277.

${ }^{2}$ J. M. R. Stone and I. M. Mills, Mol. Phys. 18, 631 (1970).

${ }^{3}$ F. A. Miller and R. J. Capwell, Spectrochim. Acta Part A 27, 1947 (1971).

${ }^{4}$ (a) W. Kiefer, H. J. Bernstein, M. Danyluk, and H. Wieser, Chem. Phys. Lett. 12, 605 (1972); (b) J. Mol. Spectrosc. 43, 393 (1972).

${ }^{5}$ J. R. Durig and L. A. Carreira, J. Chem. Phys. 56, 4966 (1972).

${ }^{6}$ T. H. Chao and J. Laane, Chem. Phys. Lett. 14, 595 (1972).

'J. R. Durig, L. A. Carreira, and J. N. Willis, Jr., J. Chem. Phys. 57, 2755 (1972).

${ }^{8}$ L. A. Carreira, R. O. Carter, and J. R. Durig, J. Chem. Phys. 57, 3384 (1972).

${ }^{9}$ J. R. Durig, A. C. Shing, L. A. Carreira, and Y. S. Li, J. Chem. Phys. 57, 4398 (1972).

${ }^{10}$ J. R. Durig, A. C. Shing, and L. A. Carreira, J. Mol. Struct. 17, 423 (1973).

${ }^{11}$ J. R. Durig, R. O. Carter, and L. A. Carreira, J. Chem. Phys. 59, 2249 (1973).

${ }^{12}$ J. D. Lewis, T. H. Chao, and J. Laane, J. Chem. Phys. 62, 1932 (1975).

${ }^{13}$ J. R. Durig, W. E. Bucy, L. A. Carreira, and C. J. Wurrey, J. Chem. Phys, 60, 1754 (1974).

${ }^{14} \mathrm{~J}$. R. Durig, W. E. Bucy, and C. J. Wurrey, J. Chem. Phys. 60, 3293 (1974).

${ }^{15} \mathrm{~J}$. R. Villareal and J. Laane, J. Chem. Phys. 62, 303 (1975).

${ }^{16}$ J. R. Durig, A. D. Lopata, and C. J. Wurrey, J. Raman Spectrosc. 3, 345 (1975).
${ }^{17}$ S. Brodersen, in Raman Spectroscopy of Liquids and Gases, edited by A. Weber (Springer, Berlin, 1979), pp. 7-69.

${ }^{18}$ (a) D. F. Bocian, G. A. Schick, and R. R. Birge, J. Chem. Phys. 74, 3660 (1981); (b) 75, 2626 (1981); (c) 75, 3215 (1981).

${ }^{19}$ R. R. Birge, J. Chem. Phys. 72, 5312 (1980).

${ }^{20}$ J. Applequist, J. R. Carl, and K.-K. Fung, J. Am. Chem. Soc. 94, 2952 (1974).

${ }^{21} \mathrm{H}$. A. Lorentz, Ann. Phys. (Leipzig) 9, 641 (1880); L. Lorenz, ibid. 11, 70 (1880).

${ }^{22}$ Handbook of Chemistry and Physics, 58th ed., edited by R. C. Weast (Chemical Rubber, Cleveland, 1977).

${ }^{23}$ D. A. Long, Raman Spectroscopy (McGraw-Hill, New York, 1977), pp. 41-86.

${ }^{24}$ J. A. Greenhouse and H. L. Strauss, J. Chem. Phys. 50, 124 (1969).

${ }^{25}$ J. D. Lewis, T. B. Malloy, Jr., T. H. Chao, and J. Laane, J. Mol. Struct. 12, 427 (1972).

${ }^{26}$ (a) I. M. Mills, Mol. Phys. 7, 549 (1964); (b) 8, 363 (1964).

${ }^{27}$ H. M. Pickett and H. L. Strauss, J. Chem. Phys. 55, 324 (1971).

${ }^{28} \mathrm{~J}$. E. Wollrab, Rotational Spectra and Molecular Structure (Academic, New York, 1967), pp. 145-202.

${ }^{29} \mathrm{C}$. Flanagan and L. Pierce, J. Chem. Phys. 38, 2963 (1963).

${ }^{30}$ J. B. Hendrickson, J. Am. Chem. Soc. 89, 7036 (1967).

${ }^{31}$ C. C. Costain, J. Chem. Phys. 29, 864 (1958).

${ }^{32}$ W. G. Fateley and F. A. Miller, Spectrochim. Acta 19, 611 (1963).

${ }^{33}$ J. R. Durig, C. M. Player, and J. Bragin, J. Chem. Phys. 54,460 (1972).

${ }^{34}$ J. M. Sichel and M. A. Whitehead, Theor. Chim. Acta 7, 32 (1967). 